\title{
"Museologia colaborativa": diferentes processos nas relações entre antropólogos, coleções etnográficas e povos indígenas
}

"Collaborative museology": different processes in relationships among anthropologists, ethnographic collections, and indigenous peoples

Adriana Russi ${ }^{*, \star *}$

* Universidade Federal Fluminense - Rio das Ostras, RJ, Brasil

** Universidade de São Paulo - São Paulo, SP, Brasil

Em pós-doutoramento adri.russitm@gmail.com

https://orcid.org/0000-0003-0738-1558

Regina Abreu ${ }^{\star * *}$

*** Universidade Federal do Estado do Rio de Janeiro - Rio de Janeiro, RJ, Brasil abreuregin@gmail.com

https://orcid.org/0000-0002-3880-1749 


\title{
Resumo
}

Os museus antropológicos exercem relevante papel na preservação dos patrimônios materiais. Antropólogos, entre outros, contribuem para o colecionamento, documentação, pesquisa e curadoria de exposições sobre diferentes povos e culturas. Nas últimas décadas, cunhou-se a expressão "museologia colaborativa" para expressar uma ação de inclusão e diálogo com remanescentes de povos cujos objetos foram musealizados. Reconfigurando práticas nos museus, tais ações impactaram particularmente as relações entre antropólogos e povos indígenas. Essas experiências dialógicas, em contextos nacionais e internacionais, envolvem antropólogos, profissionais de museus, povos indígenas, museus e coleções. São diferentes processos que apontam para um exercício colaborativo e simétrico entre aqueles que estudam e representam as diferentes culturas e aqueles que as vivenciam cotidianamente. Analisando a literatura sobre o tema, este artigo dialoga com experiências de campo, trazendo dados sobre a "museologia colaborativa" no Museu de Arqueologia e Etnologia da UFSC, em Florianópolis, e no Museu Paraense Emílio Goeldi, em Belém.

Palavras-chave: museologia colaborativa; coleções etnográficas; antropólogos; povos indígenas.

\begin{abstract}
Anthropological museums play a relevant role in the preservation of material heritage. Anthropologists, among others, contribute to the collection, documentation, research and curation of exhibitions on different peoples and cultures. In the last decades, the expression "collaborative museology" has been coined to express an action of inclusion and dialogue with remnants of peoples whose objects have been musealized. By reconfiguring practices in museums, such actions particularly impacted relations between anthropologists and indigenous peoples. These dialogic experiences, in national and international contexts, involve anthropologists, museum professionals, indigenous peoples, museums and collections. They are different processes that point to a collaborative and symmetrical exercise between those who study and represent the different cultures and those who experience them daily. Analyzing the literature on the subject, this article talks with field experiences, bringing data about "collaborative museology" at the Museum of Archeology and Ethnology of UFSC, in Florianópolis, and the Emílio Goeldi Museum in Belém.
\end{abstract}

Keywords: collaborative museology; ethnographic collections; anthropologists; indigenous people. 


\section{Introdução}

Nas ultimas décadas, acompanhamos uma virada teórico-epistemológica no campo dos museus e da antropologia que traz novos alentos, particularmente aos museus antropológicos ou etnográficos. Um interessante mas também controverso debate vem ocorrendo e se volta às relações que ocorrem entre os museus, suas coleções, seus profissionais, os antropólogos e os remanescentes de povos cujos objetos encontram-se nos acervos dos museus.

Em suas origens, a antropologia, integrando o conjunto dos saberes enciclopédicos das ciências de finais do século XIX, era produzida nos museus - as grandes casas onde se praticava a pesquisa científica. Naquele contexto os objetos eram colecionados como testemunhos e provas materiais das diferentes culturas. A produção do conhecimento antropológico atravessou o século XX e adentrou o século XXI no diálogo com os museus, embora possamos apontar importantes inflexões. A partir dos anos 1920, com a antropologia relativista, inaugurada pelos estudos de Franz Boas e Bronislaw Malinowski, ocorre progressivamente um deslocamento das pesquisas para as universidades, centros e laboratórios de pesquisas. Esse deslocamento afetou o papel dos museus na produção do conhecimento antropológico, mas não chegou a interferir no lugar dos museus como centros de colecionamento de cultura material, documentação e exibição a partir de pesquisas etnográficas. Muitos antropólogos, inclusive o próprio Franz Boas, criticaram os museus etnográficos, reivindicando uma renovação dos ambientes de pesquisa, ensino e reflexão para a antropologia cultural e social. A tensão entre antropologia e museus chegou a alguns momentos difíceis, como em 1968, quando William Sturtevant colocou uma interrogação que produziu inúmeros debates: “Does anthropology needs museums?" Na época, Sturtevant, seguido de outros antropólogos, considerava que a antropologia praticada nas universidades se distanciava do modelo de antropologia praticado nos museus: a primeira se concentrava na pesquisa de campo com observação participante e registros escritos; a segunda, com a coleta e exposição de objetos. Após muitos debates, o lugar dos museus antropológicos ganhou gradativamente novas configurações. Contribuiu para essa renovação a busca por formas mais simétricas de diálogo entre antropólogos e remanescentes de povos e culturas pesquisados. Além disso, o próprio campo dos museus conheceu um vigoroso movimento a partir da segunda metade do século XX, que passou a ser conhecido como Nova 
Museologia. Este movimento, do qual foram precursores alguns antropólogos como Hugues de Varine, foi demarcado na mesa-redonda de Santiago do Chile, em 1972, quando se realizaram debates entre profissionais dos museus, sendo traçadas importantes diretrizes que delinearam toda uma nova forma de pensar o museu e a museologia ao reforçar a integração entre museu e sociedade; era a ideia do "museu integral". Os desdobramentos do movimento da Nova Museologia gerou novas formas de pesquisa, colecionamento e exposições e também novas formas de museus como os ecomuseus, os museus de território, os museus comunitários e os museus sociais. ${ }^{1}$

A partir dos anos 1990, prolongando-se para o século XXI, os museus antropológicos ou etnográficos, mobilizados pelo acúmulo dos debates no campo da antropologia e no campo da "nova museologia", colocam em pauta a revisão sobre sua função social, sua forma de expor e apresentar/representar o "outro", além do seu lugar na conservação e produção de conhecimento. Como afirma Dias (2007, p. 126):

[...] os museus etnográficos parecem estar num estado de crise permanente que se manifesta nos países europeus através da sua renovação ou transformação radical. São numerosos os debates, as mesas-redondas e os colóquios dedicados ao presente e ao futuro dessas instituições. Que fazer com os museus de etnografia? [...] qual o papel do museu enquanto espaço de mostra das diferenças culturais na época da globalização?

Além desses debates, nas últimas décadas do século XX, os movimentos sociais acionaram com vigor novas agendas e exigências. Povos tradicionais e não ocidentais, que antes eram representados em grandes museus por meio de acervos muitas vezes conquistados em saques de empresas coloniais, em movimentos de cunho identitário reivindicaram reconhecimento e protagonismo na cena pública. Aqueles, antes tradicionalmente identificados como "outros" a partir da tradição colonial europeia, exigiram um "lugar de fala" na primeira pessoa.

Esses movimentos tiveram impactos nos chamados "museus tradicionais" do Ocidente. Muitas foram as demandas, desde o desejo de repatriação de

1 Ver Dias (2007, 2013); Abreu (2007); Gordon e Silva (2005), Arantes Neto (2005), Cury e Silva (2008) e Schwarcz (2013). 
objetos a interferências e reformulações de exposições a partir das leituras dos próprios interessados sobre suas culturas. O monopólio do saber e das interpretações sobre as culturas deixou de ser dos estudiosos e passou a ser um lugar de disputas entre diferentes pontos de vista.

Assim, nos chamados "museus tradicionais" e, em particular, nos museus antropológicos e etnográficos, gradualmente se experimentam novas práticas museológicas, indo desde o processo do colecionamento e documentação até o processo de exposição ou difusão do conhecimento produzido. Essas práticas se abrem a participação plural de equipes interdisciplinares com representantes de movimentos sociais e remanescentes de povos e culturas que o museu se propõe a estudar e representar. Tal tendência tem sido identificada de maneira geral pela expressão "museologia colaborativa" ou "museologia compartilhada" e tem despertado o interesse de estudos contemporâneos. Um conjunto de verbos se associa a esses processos, entre eles: participar, colaborar, compartilhar, analisar, criticar, comentar, opinar, discordar, reivindicar. No caso de museus com coleções etnográficas de povos indígenas, como ocorre em museus brasileiros, tais como o Museu do Índio, o Museu de Arqueologia e Etnologia da Universidade de São Paulo, o Museu Goeldi, o Museu Nacional, muitas têm sido as descrições sobre os diferentes processos de negociações entre pesquisadores, profissionais de museus e os próprios indígenas.

Neste artigo apresentamos uma reflexão sobre esse tema, ancoradas em nossas práticas e recentes pesquisas. ${ }^{2}$ No Brasil, essas mudanças expressaram-se também em novas políticas públicas, especialmente na Política

2 Entre elas destacamos a pesquisa de pós-doutoramento de Adriana Russi no MAE/USP, ainda em andamento, denominada Nas fronteiras dos museus: processos museológicos compartilhados com povos indígenas em museus de antropologia e etnologia no Brasil. Salientamos ainda o artigo de Regina Abreu (2003) sobre a experiência dos índios wajãpi no Museu do Índio, no Rio de Janeiro, uma das primeiras experiências de exposição compartilhada no Brasil no contexto da emergência da nova Política Nacional de Museus. Regina Abreu (2014) também analisa quatro experiências pioneiras de curadorias compartilhadas entre antropólogos e indígenas no Brasil. A primeira envolveu o antropólogo João Pacheco de Oliveira, a artista plástica Jussara Gruber e o povo Tikuna em 1990 e originou o Museu Magüta em Benjamin Constant, Amazonas. A segunda envolveu os antropólogos Dominique Gallois e José Carlos Levinho e os índios wajãpi em 2000 numa exposição sobre a cultura wajãpi, no Museu do Índio. A terceira envolveu a antropóloga Lux Vidal e os povos do Oiapoque numa exposição no Museu do Índio, em 2007. A quarta, novamente com a antropóloga Lux Vidal e os povos do Oiapoque, culminou com a criação do Museu Kuahi, em 2007 (ver também Abreu, 2013). 
Nacional dos Museus (Brasil, 2003) que, a partir de amplo debate com diferentes setores da sociedade, incorporou tendências do movimento da Nova Museologia ${ }^{3}$ e da museologia social. ${ }^{4}$ Entre seus princípios norteadores, destacamos a participação das comunidades nas tomadas de decisões nos contextos e nas práticas dos museus. Museus antropológicos ou etnográficos, especialmente aqueles com acervos de povos indígenas, vêm revendo suas práticas em novas propostas de trabalho que consideram a interdisciplinaridade integrada a atitudes mais inclusivas que respeitam o protagonismo indígena. Alguns antropólogos mais diretamente ligados a essas novas experiências registraram tais mudanças, problematizando os desafios que ocorrem em negociações nesses contextos. ${ }^{5}$ Esses processos museológicos, quando relacionados aos chamados "outros", têm se beneficiado das contribuições das diferentes formas de participação dos povos indígenas.

Paralelamente, a mobilização dos grupos indígenas levou a uma descoberta dos museus pelos indígenas que passaram desde os anos 1990 a criar seus próprios museus. O Museu Magüta, do povo Tikuna, na cidade de Benjamin Constant, tornou-se um símbolo, premiado pelo International Council of Museums (ICOM) e reconhecido como emblema da luta dos povos indígenas por direitos e garantias constitucionais. ${ }^{6}$ Outras experiências mais recentes de apropriação pelos indígenas do museu como equipamento cultural são descritas como importantes iniciativas de fortalecimento das formas de organização política desses povos e de reverberação de suas vozes (Cury, 2013; Françozo; Van Broekhoven, 2017; Lima Filho; Athias, 2016).

Neste artigo, nosso olhar recai sobre algumas experiências de práticas colaborativas em museus antropológicos ou etnográficos, especialmente relacionados a acervos indígenas. Nos casos pesquisados, refletimos sobre algumas das consequências desse trabalho compartilhado entre antropólogos e indígenas junto a algumas coleções. Procuramos perceber como essas coleções são

3 Sobre o Mouvement international pour une nouvelle Muséologie (MINOM), ver Desvalées e Mairesse (2013) e Duarte (2013).

4 Sobre a museologia social ver Chagas e Gouveia (2014).

5 Destacamos as contribuições de como Velthem (2012), Cury, Vasconcellos e Ortiz (2012), Athias (2015) e Abreu (2007).

6 Ver Velthem (2003), Abreu (2005), Bessa Freire (2009). 
objetos de ressignificação e de requalificação por parte dos indígenas e como esses novos olhares sobre os objetos trazem outras perspectivas tanto para os museus quanto para os povos indígenas. Podemos dizer que esse movimento altera o sentido dos museus de representações sobre os "outros" para representações com os "outros".

\section{Museus antropológicos ou etnográficos e novos processos museológicos: de práticas de representação sobre os "outros" para práticas de representação com os "outros"}

Da criação dos primeiros museus etnográficos na Europa no século XIX - tal como o seminal Musée d'Ethnografie du Trocadéro, fundado em Paris, em 1878 - até os dias de hoje, os objetos e as coleções passaram por diferentes diretrizes conceituais. ${ }^{7}$ É bem conhecido o debate impulsionado por Paul Rivet ${ }^{8}$ e Georges Henri Rivière ${ }^{9}$ que transformaram esse primeiro grande museu de etnografia no Musée de l'Homme, um museu antropológico impulsionado pela moderno conceito antropológico de cultura, movido pelos ideais da diversidade das culturas humanas e da igualdade biológica de nossa espécie. Esse modelo de museu inspirou muitos outros pelo mundo e teve no Brasil os seus adeptos, gerando, por exemplo, o Museu do Homem do Nordeste, que se mantém até hoje em Recife. ${ }^{10}$

Embora tenha havido um esforço por parte de alguns antropólogos e profissionais de museus no sentido de circunscrever o campo específico do museu antropológico e/ou do museu etnográfico, é importante sinalizar que a relação entre o campo da antropologia e o dos museus segue um dinamismo próprio que se diferencia em contextos específicos. O sistema de classificação dos museus não segue um percurso cartesiano, tornando frágeis quaisquer

7 Sobre este tema, ver Dias (1991).

8 Fundador do Musée de l'Homme, que em 1973 substituiu o Musée d'Ethnografie du Trocadéro, localizado em Paris.

9 Cofundador do Musée de l'Homme, autor de La museología (Rivière, 1993), importante protagonista da Nova Museologia.

10 Sobre a apropriação do ideário do Musée de l'Homme no Brasil e, especificamente, sobre o Museu do Homem no Nordeste, ver Chagas (2009). 
tentativas de linearização. Encontramos muitas coleções etnográficas reunidas por antropólogos como partes de suas pesquisas em museus de ciência, antigos museus enciclopédicos, museus históricos ou museus de arte. A pouca racionalidade das classificações dos museus e a incorporação de acervos pelas instituições reflete mais contingências históricas e políticas do que quaisquer perspectivas acadêmicas ou científicas. Coleções que chamamos de "antropológicas" são em geral provenientes de fontes muito desiguais, como pesquisas antropológicas, doações ou mesmo saques coloniais, troféus de guerras e objetos recolhidos por repressões policiais. Essas coleções integram os acervos dos mais diferentes tipos de museus. Essa ressalva relativiza o próprio conceito de museu antropológico e/ou museu etnográfico com o qual trabalhamos neste artigo. Embora focalizemos dois casos de museus que podem ser classificados como "museus antropológicos", o conjunto de nossa reflexão sobre "museologia colaborativa ou compartilhada" extrapola esses espaços, se espraiando em outros contextos museológicos.

O caso brasileiro é um bom exemplo. Muitas coleções antropológicas e, em especial, relativas a povos indígenas, como as do Museu Nacional do Rio de Janeiro (cuja coleção etnológica foi praticamente dizimada pelo trágico incêndio de setembro de 2018), as do Museu do Índio, as do Museu de Arqueologia e Etnologia da Universidade de São Paulo (MAE/USP), as do Museu Paraense Emílio Goeldi (MPEG) e outras, resultaram de fontes muito diversificadas. Além de coleções resultantes de pesquisas antropológicas em sentido estrito, encontramos doações, compras ou trocas realizadas por governantes, viajantes, militares, comerciantes, missionários e pesquisadores, e também objetos advindos de saques e guerras coloniais, de guerras tribais e de repressões policiais a cultos e rituais de diferentes povos. Essas coleções trazem à tona, portanto, diferentes perspectivas ideológicas, pois se constituíram a partir de distintos projetos. Convivem lado a lado coleções resultantes de pesquisas antropológicas com as de projetos coloniais (Cannizzo, 1998 apud Velthem, 2012).

Além disso, muitas pesquisas antropológicas que redundaram em coleções de cultura material também partiram de matrizes conceituais muito diversas e até opostas, como foi o caso dos projetos de Franz Boas e os de Otis Mason. Se o primeiro compreendia a cultura material como expressão da diversidade cultural, o segundo partia de uma perspectiva evolucionista. As diferenças de abordagem e de projetos implicaram diferentes formas de colecionamento e de exposições. 
Nos anos 1980, certamente as teorias do pós-colonialismo ${ }^{11}$ contribuíram para uma revisão crítica das ciências sociais, o que repercutiu também no universo museal. A noção de fronteira como um "entre-lugar", apenas para citar um conceito importante para Homi Bhabha (1998), suscitou questionamentos aos museus que dispunham de coleções antropológicas ou etnográficas. A colonialidade se faz presente hoje em países que há décadas são ex-colônias como uma espécie de fantasma do passado. Transpor as mazelas socioeconômicas e políticas deixadas pelas experiências coloniais é um dos desafios que ainda hoje enfrentamos e que repercute no universo museológico.

Paralelamente, o vigoroso movimento da Nova Museologia que ganhou inúmeros adeptos entre museólogos e profissionais de museus em contextos internacionais, impulsionado pela atuação do ICOM, desdobrou-se e ampliou-se com novos movimentos voltados para propor uma museologia afeita às comunidades, especialmente, as populações periféricas e invisibilizadas nos centros urbanos e nas áreas rurais. A chamada museologia social despontou como uma alternativa para muitas populações que viram na criação de museus comunitários uma importante ferramenta para agregar apoios e dinamizar suas bandeiras de luta. ${ }^{12}$ Outros movimentos se sucederam e se somaram nessa direção, como o da "museologia crítica". ${ }^{13}$ Este último associou-se a debates das

11 Se por um lado os autores pós-coloniais como Bhabha (1998), Stuart Hall (2009), Edward Said (2007) se aproximaram das correntes pós-modernas e pós-estruturalistas, os autores decoloniais estão associados a projetos e autores de esquerda. Nesse sentido, estes últimos buscam uma articulação interdisciplinar e uma emancipação teórico-intelectual. O termo "decolonialidade" parece surgir no sentido de superar as polarizações binárias, como colonizador e colonizado. Paralelamente, se fortalecem movimentos sociais dos grupos minoritários, debatendo e exigindo seus direitos. No Brasil, desde os anos 1980 observamos o crescimento das organizações indígenas, por exemplo. Sobre pós-colonialismo e decolonialismo, ver Ballestrin (2013).

12 Resumidamente, a museologia social constitui uma tomada de posição com relação à aproximação dos museus com a sociedade, especialmente com as populações periféricas. Temas como "direito à memória" ou "direito ao patrimônio" passaram a ser acionados, numa crítica ao que era considerada uma postura "elitista" dos chamados "museus tradicionais". Ver Moutinho (1993) e Chagas e Gouveia (2014).

13 Pierre Bourdieu (2007), seguido de outros pesquisadores, se voltou a estudos críticos dos "museus tradicionais". Em sua pesquisa, Bourdieu aponta para a inacessibilidade dos museus para as classes populares. Outro pesquisador crítico sobre os museus foi Anderson (2008), que identificou a relevância do papel dos museus na construção do ideal nacional. A chamada museologia crítica, proposta por Santacana Mestre e Hernández Cardona (2006), aponta as incongruências e contradições de certos processos museológicos. 
chamadas teorias do pós-colonialismo, defendendo a função social dos museus e o incremento de outras formas de diálogo entre profissionais dos museus e diferentes segmentos sociais. Essas inquietações trouxeram também para o campo museológico o tema das diferenças culturais e das diferentes formas de apropriação dos projetos propostos pelos museus por parte de uma sociedade plural e multicultural (Bhabha, 1998).

No contexto internacional, salientamos alguns debates que impactaram o campo da antropologia. O "desmonte" do Musée de l'Homme em Paris e a criação, em 2006, do Musée du quai Branly trouxeram à tona uma multiplicidade de questões, protestos, movimentos e reflexões. A questão central dizia respeito ao fato de que as coleções de objetos de povos não ocidentais, que durante anos ficaram sob a guarda do Musée de l'Homme, foram transferidas para o novo museu por determinação direta do governo francês. Os argumentos eram diversos. Falava-se da pouca visitação do Musée de l'Homme, do envelhecimento de um estilo de museu antropológico, da necessidade de reconfiguração dos museus nacionais na França. $\mathrm{O}$ fato que mais chamava a atenção era o interesse do próprio presidente da República, Jacques Chirac, no empreendimento, sendo ele próprio um grande colecionador de objetos oriundos de povos não ocidentais. Muitos antropólogos protestaram e chegaram a criar uma barreira humana para impedir a retirada dos objetos do Musée de l'Homme. Mas a mudança ocorreu, suscitando um movimento intenso de reflexões que ainda hoje reverberam no campo da antropologia e dos museus. Benoît de L'Estoile (2007) escreveu um livro sobre o tema, contribuindo para colocar a problemática sobre as coleções de povos não ocidentais e as relações entre antropologia e museus no centro dos debates políticos e acadêmicos. $\mathrm{O}$ caso francês trouxe muitas questões sobre o estatuto dos objetos oriundos de povos não ocidentais. Uma onda de reflexões sobre os legados coloniais e os objetos dos "outros" nos grandes museus europeus, americanos e canadenses girou em torno das representações de alteridade produzidas nesses acervos e de ações para descolonizá-las, propondo novos olhares para essas coleções.

No campo da museologia, autores como Christina Kreps (2003) apontavam para práticas curatoriais baseadas na perspectiva cross-cultural, ou seja, práticas inter ou transculturais que reconhecessem outras formas não ocidentais de preservação e musealização. 
A problematização do discurso hegemônico a partir dos países centrais se instalou e novas formas de narrativas passaram a ser propostas. Algumas delas se construíram a partir da aproximação do museu e de seus profissionais com o "outro". Tais práticas buscavam a polifonia, apostando numa forma colaborativa entre profissionais de museus, antropólogos e povos indígenas para a formação de coleções, a produção de conhecimento sobre os objetos e a concepção de exposições.

Esse movimento de reflexão a partir de teorias pós-coloniais encontrou terreno fértil no fortalecimento de movimentos sociais e identitários de povos indígenas e remanescentes dos povos cujos acervos encontravam-se nesses grandes "museus tradicionais" ou em museus antropológicos. Como afirmou Marshall Sahlins (1997), representantes de povos tradicionais em processos de valorização de suas culturas passaram paulatinamente a assumir protagonismo em projetos que diziam respeito aos seus interesses. A descrição de Shepard et al. (2017, p. 766) sobre os movimentos sociais, sobretudo os movimentos dos povos indígenas e as crescentes reivindicações de interlocução direta com Estados-nações, cada vez mais fundados em direitos, sobretudo em "direitos coletivos", apresenta a dimensão dessas amplas movimentações e construções de protagonismos:

[...] a partir dos anos de 1970, bem como com o crescimento demográfico de povos indígenas na América do Sul - muitos destes, anteriormente considerados à beira da extinção [...] a titulação de vastas terras indígenas, especialmente no Brasil, e o ressurgimento de novas identidades, esses povos têm conquistado, no Brasil e em outros países, novas modalidades de inserção e de interlocução com os Estados-nação, assim como com a própria disciplina da antropologia [...]. Essas mudanças de paradigma pedem um novo modelo para a museologia etnográfica [...] e para o conceito geral de patrimônio cultural indígena [...].

\section{Políticas culturais e de museus no Brasil e a questão indígena}

A análise de processos museológicos colaborativos que envolvem povos indígenas remete às políticas de cultura e às questões indígenas. João Domingues descreve as mudanças implementadas nas políticas públicas para a área da 
cultura no Brasil, a partir da entrada de Gilberto Gil como ministro da cultura em 2003. Naquele momento, evidenciaram-se os impactos das pressões dos movimentos sociais para a elaboração de políticas que se constituíssem no diálogo com as bases da sociedade (Domingues, 2010).

Domingues aponta ainda o conceito antropológico de cultura como um das novidades no campo das políticas públicas de cultura no Brasil. Essa acepção de cultura e a noção de diversidade e pluralidade que lhes são intrínsecas já repercutiam internacionalmente em convenções e conferências promovidas pela Unesco. ${ }^{14}$ Em 1996, com a publicação do relatório da Comissão Mundial de Cultura e Desenvolvimento, intitulado Nossa diversidade criadora, a Unesco estabelece uma agenda centrada na noção de diversidade cultural como eixo para ações em diversos campos. ${ }^{15}$

Com o processo de democratização do Estado brasileiro nos anos 1980, houve um crescimento do debate e participação de movimentos sociais e identitários, ampliando-se a representatividade de diferentes segmentos, notadamente dos povos indígenas em fóruns políticos que discutiam programas nacionais. A Constituição de 1988 refletiu essa participação ampliada de diferentes segmentos, que conquistaram espaços decisivos de defesa de direitos coletivos. ${ }^{16}$ Os artigos 231 e 232 marcaram um importante avanço nesse sentido, assegurando os direitos à livre determinação dos povos indígenas em suas formas de organização social, costumes, línguas, crenças e tradições. Da mesma maneira, as discussões sobre o entendimento acerca do "patrimônio cultural brasileiro" também ganharam destaque nos artigos 215 e 216. Nesses artigos fica expresso que integram o "patrimônio cultural brasileiro" tanto o patrimônio material (edificado ou não) quanto aquele que passou a ser identificado como "patrimônio imaterial", reconhecendo a importância da memória dos diferentes grupos formadores da sociedade brasileira.

A partir de 2003, o Ministério da Cultura (MinC) instituiu grupos de trabalho para identificar demandas específicas como a questão das culturas

14 Sobre o papel da Unesco no campo dos patrimônios e museus, ver Abreu (2015).

15 O relatório foi publicado no Brasil em 1997 (ver Pérez de Cuéllar, 1997).

16 No artigo $215, \S 1^{\circ}$ do texto constitucional, consta que: "O Estado protegerá as manifestações das culturas populares, indígenas e afro-brasileiras, e das de outros grupos participantes do processo civilizatório nacional" (Brasil, 1992). 
indígenas. Conforme salienta Russi (2014), o Prêmio Culturas Indígenas foi idealizado para ser concedido anualmente e resultou de propostas identificadas pelo Grupo de Trabalho para as Culturas Indígenas do MinC. ${ }^{17}$ Em 2012, aprovou-se o Plano Setorial para Culturas Indígenas do MinC (PSCI), criado no contexto das políticas indigenistas. Essa ação do MinC tinha por objetivo colaborar para concretizar os direitos dos povos indígenas, criando condições para o exercício da "cidadania cultural" desses povos. As ações do plano se voltaram à proteção, promoção, fortalecimento e à valorização das culturas indígenas, a partir da intensa participação dos povos indígenas em sua concepção e implementação.

No PSCI, a ênfase que se dá aos textos legais relativos à preservação da diversidade cultural não é mais a do contexto de "multiculturalidade", mas de "interculturalidade". ${ }^{18} \mathrm{~A}$ tônica deixou de ser a da tolerância (que muitas vezes supunha distanciamento) e passou a ser ancorada na ideia de confluência, interação entre culturas diversas, que subentende a "incorporação recíproca e convivência ativa", sendo essa a ideia de "interculturalidade" presente no documento do PSCI.

Assim, se por um lado vemos os antropólogos atuarem nesse "cenário", por outro tem sido cada vez mais ativa a participação de representantes das populações interessadas, notadamente, os povos indígenas, quilombolas e um conjunto de "populações tradicionais". O que queremos evidenciar é que concomitantemente tínhamos, por um lado, o esforço do governo de implementar políticas de cultura voltadas aos povos indígenas e, por outro, o incentivo, ou melhor, a prerrogativa que o plano e suas ações estivessem calcados na intensa participação social dos povos indígenas, remetendo à participação dos "novos sujeitos de direito coletivo no Brasil". E os antropólogos passaram a ocupar relevante papel nesse campo de negociações e disputas.

Apesar desses avanços, recentes debates evidenciam que ainda persistem dificuldades para que se efetive o direito constitucional desses povos (Museu do Índio, 2013). A gestão de patrimônios culturais indígenas deveria se tornar

17 O prêmio subordina-se aos princípios enunciados no artigo 215 da Constituição Federal e está vinculado à Lei Rouanet, ao Programa Mais Cultura e ao Programa Cultura Viva do MinC.

18 O antropólogo Néstor García Canclini (2009) foi um dos autores usados como referência sobre o tema "interculturalidade", na elaboração do PSCI. 
uma preocupação central nas políticas públicas indigenistas e culturais no Brasil, hoje fortemente abaladas pela crise política e econômica que afeta nosso país. Essa tensão aponta muitos desafios ao campo das relações entre antropólogos, museus e povos indígenas.

O cenário sobre políticas para museus no Brasil acompanhou articulações e ações internacionais. Retomando um pouco do percurso histórico, um ano depois da criação da Unesco, em 1945, vimos surgir o International Council of Museums (ICOM) - e, apenas dois anos depois, foi criado o Comitê Brasileiro do ICOM. O mundo dos museus se instaurou no Brasil ainda no século XIX e o campo propriamente da museologia remete aos anos 1930, quando da instituição do primeiro curso de museologia no Rio de Janeiro. Desde então, seus profissionais foram cada vez mais atuantes na defesa desse campo profissional, reconhecendo esta como uma área importante do conhecimento.

Desde os anos 1970 ou talvez antes disso, dentre as tendências da museologia brasileira observamos aquelas mais progressistas na relação do museu com a sociedade. A declaração oriunda da já citada mesa-redonda de Santiago do Chile, de 1972, ecoa em nosso país desde então, primeiro com a tendência da Nova Museologia nos anos 1980, e uma década depois com a chamada museologia social ou sociomuseologia. ${ }^{19}$ Tais tendências enfatizam a função social do museu num diálogo estreito com a comunidade ao incorporar suas demandas e problemas. O museu se coloca a serviço da sociedade.

Como vimos, os anos 1960 e 1970 foram marcados por questionamentos quanto às relações estabelecidas entre museus, museologia e antropologia. Nos anos 1980, processos decoloniais suscitaram críticas ao ambiente museal, ao salientar que as práticas museológicas, particularmente aquelas dos museus de etnografia, eram intrinsecamente ligadas a projetos coloniais. Segundo Durand (2007, p. 375):

No caso da etnomuseologia combinou-se também com a emergência, a partir dos anos 60, das ideias (no fundo igualmente ligadas à crítica do saber canónico) que é possível agrupar debaixo das bandeiras da "nova museologia" e dos "ecomuseus": contribuição para um "melhor conhecimento delas próprias" por

19 Ver Chagas e Gouveia (2014); Moutinho (2014). 
parte das populações envolvidas, ancoragem territorial, descentralização, interdisciplinaridade, contextualização, promoção do "desenvolvimento sustentado" através da "identidade", participação em vez de autoridade [...]. ${ }^{20}$

No Brasil, já em 1986, tivemos a idealização do Sistema Nacional de Museus, com vistas a articular as instituições museais e a estabelecer padrões mínimos para seu funcionamento. Uma figura expoente desse momento foi Waldisa Rússio (Carvalho, 2011), para quem a musealização é tomada como prática social e jogo de representação de memórias.

As mudanças dos paradigmas para as políticas culturais brasileiras de 2003 incluíram a organização do setor museológico nacional a partir de linhas programáticas. No âmbito de políticas públicas de caráter mais amplo, a valorização do patrimônio cultural foi dispositivo para o aprimoramento de processos democráticos, sendo os museus tomados como práticas e processos socioculturais a serviço da sociedade e de seu desenvolvimento.

Resumidamente, o objetivo da Política Nacional de Museus (PNM) é o de:

[...] promover a valorização, a preservação e a fruição do patrimônio cultural brasileiro, considerado como um dos dispositivos de inclusão social e cidadania, por meio do desenvolvimento e da revitalização das instituições museológicas existentes e pelo fomento à criação de novos processos de produção e institucionalização de memórias constitutivas da diversidade social, étnica e cultural do país. (Brasil, 2003, p. 8).

Com a centralidade que ganharam no panorama político e cultural do mundo contemporâneo, os museus foram tomados como "práticas sociais complexas" (Brasil, 2007). Tratava-se de premissa associada a um novo projeto de nação mais inclusivo e com maiores estímulos à participação cidadã. Um dos sete eixos programáticos da PNM - o da democratização e acesso aos bens culturais - remete diretamente a processos participativos, o que estimula práticas colaborativas com povos indígenas.

20 Nessa passagem do texto, o autor remete suas ideias ao regulamento do Mouvement international pour une nouvelle Muséologie (Mouvement..., 1987). 
Segundo o Instituto Brasileiro de Museus (Ibram), o panorama museal brasileiro é hoje constituído por quase quatro mil museus. A partir de dados disponíveis no Guia dos museus brasileiros, identificamos 457 museus classificados na tipologia "antropologia e etnografia" (Instituto Brasileiro de Museus, 2011). Nessa tipologia inserem-se museus e/ou "[...] coleções relacionadas às diversas etnias, voltadas para o estudo antropológico e social das diferentes culturas. Ex: acervos folclóricos, artes e tradições populares, indígenas, afro-brasileiras, do homem americano, do homem do sertão etc." (Instituto Brasileiro de Museus, 2011, p. 19).

Dentre esses 457 museus considerados como sendo "de antropologia" encontramos um universo muito diversificado de instituições, constituído por museus públicos e privados, de pequeno, médio ou grande porte. Muitos deles poderiam ser classificados como "tradicionais", outros como "ecomuseus" ou "museus comunitários". Há também os "museus universitários". Alguns têm como principal coleção os objetos etnográficos, outros são constituídos por diferentes tipologias de coleções e outros sequer têm um conjunto de objetos etnográficos. Certos museus estão instalados em edifícios de grandes dimensões, equipados com modernas reservas técnicas e conduzidos por um quadro funcional altamente qualificado. Outros se caracterizam por um amontoado de objetos, mal documentados e acondicionados, e têm numa única pessoa a figura responsável por quase todas as atividades do museu. Assim, considerando as regiões e o tipo de acervo de antropologia ou etnografia, o panorama é o seguinte: 161 museus estão na região Sul, 140 na região Sudeste, 101 na região Nordeste, 28 na região Norte, 27 museus na região Centro-Oeste.

As coleções referentes aos povos indígenas demonstram enorme potencial para processos de valorização dessas culturas (Abreu, 2005; Velthem, 2003). Ver e conhecer as peças confeccionadas por ancestrais representa uma das maneiras de acesso dos povos indígenas a aspectos de suas culturas para, a partir dessa experiência, tecer projetos para o futuro. As práticas patrimoniais estariam assim associadas ao futuro, seriam as "raízes do futuro", tecendo elos entre diferentes temporalidades, como assinalou Hugues de Varine (2013). Os museus, especialmente os museus de antropologia, foram se abrindo para novas formas de apropriação e diálogo de diferentes segmentos sociais, notadamente os povos indígenas, com o patrimônio musealizado, tornando-se "lugares onde novos significados podem ser atribuídos aos movimentos de preservação cultural e de afirmação de identidades" (Velthem, 2012, p. 58). 


\section{Indícios de mudanças: as experiências narradas por James Clifford e Michael Ames}

O antropólogo James Clifford (2016) chamou a atenção para o potencial dos museus como "zonas de contato". Em texto publicado originalmente em 1997, ele relata o encontro ocorrido em 1989, no Portland Museum of Art (Oregon, Estados Unidos), entre um grupo de velhos tlingit,, ${ }^{21}$ antropólogos e outros especialistas para conversarem sobre a Coleção Rasmussen de arte indígena da Costa Noroeste (Clifford, 1997). Por ocasião da reinstalação dessa coleção no museu, o então diretor do Portland Art Institute, Dan Monroe, sugeriu que a discussão incluísse lideranças tlingit. Assim, ao longo de três dias, indígenas (re)viram muitos objetos confeccionados por seus ancestrais. Ao contrário do que os anfitriões esperavam, os indígenas usaram a ocasião para trazerem à tona questões que na época lhes eram contemporâneas.

Os objetos eram um pretexto para que os indígenas contassem suas histórias e funcionaram como aides-mémoire e foram bons elementos para suscitar questões que afligiam aquele povo, tais como a problemática do território e a regulação de seus recursos naturais por órgãos do governo. Eram questões políticas. Cada um dos envolvidos naquele encontro tinha expectativas muito diferentes. Para os indígenas, por exemplo, era a oportunidade de estabelecer alianças e parcerias com aqueles que ali se encontravam, como antropólogos, especialistas de arte, profissionais do museu.

A equipe do museu enfrentaria dificuldades a partir daquele encontro. Depois de tantas narrativas, danças e performances dos Tlingit, que perspectiva o museu deveria priorizar? O que deveria ser enfatizado na exposição? Clifford identificou diferentes agendas naquele encontro e indagou: como acomodá-las em um mesmo projeto? O universo das representações no ambiente museal passava por muitos agenciamentos, complexidades e se configurava num lugar de cruzamentos e seleções múltiplas, traduções e apropriações.

Outras experiências dessa natureza foram postas em marcha no Canadá por pesquisadores, como o antropólogo Michael McClean Ames (1990), que no

21 Povo nativo norte-americano que vive na faixa litorânea e ilhas do Pacífico, na região que vai do sudeste do Alasca ao norte da Colúmbia Britânica, no Canadá (Clifford, 2016). 
final dos anos 1980 trabalhou com os Kwakiult.22 Ames era professor no departamento de antropologia da University of British Columbia, em Vancouver, e foi diretor do Museum of Anthropology (MOA), vinculado àquela universidade.

Em 1988, um ano antes do episódio que acompanhou no museu de Portland, Clifford também esteve trabalhando com os Kwakiult no centro cultural U'Mista e no MOA. As três instituições por onde Ames e Clifford circularam e pesquisaram: MOA, Kwagiulth Museum, em Cape Mudge, e U'Mista Cultural Centre, em Alert Bay, foram criadas na mesma época, respectivamente em 1976, 1979 e 1980.

Desde seus princípios, o MOA procurou mostrar os contatos dos europeus com as first nations, se estabelecendo como um museu articulador com outras instituições de memórias desses povos e apresentando em suas exposições os dramas e conflitos advindos dos confrontos coloniais e pós-coloniais. Nessas duas instituições de memórias locais ("tribal" memory houses), os objetos tinham múltiplos significados. Um sentido era apresentado aos visitantes externos, enquanto outro era apropriado pelos membros das comunidades locais.

À frente da direção do MOA por duas décadas (1974 a 1997), tendo voltado a essa função por dois anos antes de falecer, Ames foi considerado um grande inovador ao articular instituições através do MOA, que se tornou um campo de interseção. Como afirma Shelton (2007, p. 390), a contribuição do texto de Clifford se revela na descrição de seu campo na Colúmbia Britânica como um campo de interseção em que o museu se revelava como um lugar de relações de poder passando por mudanças e refletia "as articulações das disputas dos sentidos locais e globais".

Naquela época, o MOA se tornou local de ensino de museologia e foi reconhecido mundialmente por suas perspectivas experimentais de educação sobre a diversidade cultural. As publicações de Ames $(1985,1992)$ defendem a democratização dos museus e seu papel na promoção da colaboração através do empoderamento dos povos indígenas. Uma das estratégias que empregou nesse sentido foi a da consulta pública com as first nations sobre os objetos musealizados nas coleções e seu acesso a eles. Afinal, como os museus deveriam proceder em relação aos nativos? As diferentes posições e disputas entre

22 Os Kwakiult cuja autodenominação é Kwakwaka'wakw são um povo que vive no Canadá e ocupa o nordeste da Ilha de Vancouver e uma porção na costa continental na altura desta ilha. Ver Ribeiro (1994). 
povos nativos e museus provocou enorme debate no Canadá acerca dos parâmetros, tendo suscitado a formulação do Native American Graves Protection and Repatriation Act (NAGPRA) para a colaboração museológica. Parece que as armadilhas e os desafios para museus e antropólogos, descritos por Clifford em seu texto de 1997, continuam candentes e atuais.

Para Ames, os museus de antropologia eram instituições conservadoras que se dedicavam a apresentar uma versão positiva da história. Em sua crítica, o autor avalia a cultura dos museus e suas relações com a sociedade, indicando que os antropólogos acabavam por estereotipar as pessoas. Tanto os antropólogos quanto as instituições museológicas onde trabalham são atravessados por questões culturais, sociais, econômicas, políticas e ideológicas.

\section{A contemporaneidade brasileira e os processos colaborativos: dados preliminares de dois casos}

Como indicam Françozo e Van Broekhoven (2017), vários museus de antropologia no Brasil se dedicam a desenvolver experiências colaborativas com povos indígenas, entre os quais citamos: Museu Paraense Emílio Goeldi, Museu do Estado de Pernambuco, Museu Antropológico da Universidade Federal de Goiás, Museu Nacional do Rio de Janeiro, Museu do Índio, Museu de Arqueologia e Etnologia da Universidade de São Paulo, Museu de Arqueologia e Etnologia da Universidade de Santa Catarina e o Museu Histórico Pedagógico Índia Vanuíre, entre outros.

Acompanhamos, assim, processos museais colaborativos, denominados genericamente pela expressão "museologia colaborativa" ou "museologia compartilhada" que, como já assinalamos, refere-se a diferentes tipos de processos museológicos que resultam de interação e troca entre profissionais de instituições museológicas, e diferentes sujeitos, sobretudo diferentes grupos ou comunidades que, de alguma maneira, mantêm vínculos com o museu, entre outras relações. Dutra (2014) analisa esse fenômeno na perspectiva da "curadoria compartilhada" como prática de reconfiguração das ações educativas do museu.

Para ilustrar uma experiência nesse sentido, lembramos o caso da exposição Xavante. Em 1996, a antropóloga Sonia Dorta, que na ocasião ainda trabalhava no MAE/USP, foi convidada pela Associação Indígena Xavante Warã para colaborar com um grupo xavante a contar "o que é ser Xavante" aos moradores 
da cidade de São Paulo, através de uma exposição. A antropóloga ouvindo os velhos e as lideranças xavante concebeu com eles a exposição Xavante - Os Ritos são para Todos, que ficou em cartaz na Estação Ciência da USP e depois foi remontada em um formato menor no Teatro Tuca da Pontifícia Universidade Católica de São Paulo. Ainda em um trabalho de parceria, Sonia Dorta foi convidada um ano depois para, da mesma maneira, conceber de forma conjunta a exposição Viver a Vida Xavante, que ficou em cartaz no Museu Antropológico da Universidade Federal de Goiás. Os módulos, os objetos, os textos e legendas, tudo que foi escolhido decorreu de conversas, de diálogos e de decisões entre a curadora e os indígenas. Na época, expressões como "curadoria compartilhada" ou "museologia colaborativa" nem eram empregadas. Experiências como essa foram precursoras de uma tendência que se afirmaria posteriormente.

\section{Tecendo saberes pelos caminhos guarani, kaingang e laklãnõ-xokleng: a exposição no MArquE}

O Museu de Arqueologia e Etnologia da UFSC Prof. Oswaldo Rodrigues Cabral, o MArquE, foi inaugurado em 1965 e ocupa hoje um prédio com mais de $2000 \mathrm{~m}^{2}$. Seu acervo é constituído principalmente por objetos arqueológicos e etnográficos, com mais de 30 mil objetos musealizados. Em seu acervo etnográfico encontramos objetos dos povos Guarani, Kaingang e Laklãnõ-Xokleng e também objetos da cultura popular. Administrado pela Universidade Federal de Santa Catarina, trata-se de um museu universitário cuja trajetória está associada ao Instituto de Antropologia. Embora publicamente o MArquE afirme que suas ações colaborativas são recentes, remetendo sua narrativa à exposição Ticuna em Dois Tempos, de 2013, é possível reconhecer em suas práticas as aproximações e parcerias com os povos indígenas, ainda nos anos 1990. Mais recentemente as atividades do museu desenvolvidas com povos indígenas se concretizam através da acessibilidade ao acervo, formação e documentação de acervo, exposições, elaboração de produtos e ação educativa.

Aqui relataremos brevemente as articulações, parcerias e negociações que resultaram na exposição Tecendo Saberes pelos Caminhos Guarani, Kaingang e Laklãnõ-Xokleng. Essa exposição ficou em cartaz no MArquE de setembro de 2017 a julho de 2018, ocupando a sala de exposições de curta duração. A exposição foi uma atividade da Ação Saberes Indígenas na Escola (Asie) no âmbito 
da formação de professores indígenas guarani, kaingang e laklãnõ-xokleng, na UFSC, em torno de práticas e saberes tradicionais relacionadas à ocupação tradicional de seus territórios em Santa Catarina. Para a concepção da exposição, a equipe do MArquE considerou ser imprescindível a participação dos grupos indígenas. Convidados a participar, os professores indígenas em formação se reuniram em suas comunidades para identificar os interlocutores e os representantes que constituiriam um grupo de trabalho para realizar a exposição em conjunto com os profissionais do MArquE.

Uma das principais intenções da exposição, como atividade da Asie, era fomentar ações de valorização de saberes e práticas nas escolas e comunidades que pudessem servir para a elaboração de material didático ou paradidático usando diferentes linguagens. A intenção da exposição era mostrar processos de ensino-aprendizagem próprios, socializando aspectos sociais e culturais. Constituído o grupo de trabalho, ele foi responsável por conceber a exposição a partir de reuniões e constantes consultas à suas comunidades. Decidido sobre o que apresentariam na exposição, passaram a organizar as ideias no espaço expositivo a partir de módulos: um módulo introdutório, um módulo que apresentava a ocupação territorial desde a chegada dos europeus à contemporaneidade, um módulo dedicado à alimentação, um módulo que mostrava alguns processos artesanais como tecelagem e cestaria, um módulo dedicado a aspectos religiosos e um módulo que abordava a escola. Por decisão coletiva, todos os textos e legendas eram nas quatro línguas: nas línguas indígenas (kaingang, guarani e laklãnõ-xokleng) e em português. Conjuntamente decidiram não usar objetos do acervo do MArquE, mas objetos confeccionados especialmente para a exposição. Além da escolha dos objetos, eles também escolheram mapas, fotografias e vídeos que integravam a narrativa expositiva. O módulo introdutório, por exemplo, fazia uma clara homenagem aos anciões, àqueles que cada comunidade reconhece por sua experiência e sabedoria, através da fotografia dessas pessoas.

O museu, por sua vez, precisou aprender com todo esse processo de discussões e negociações, administrando os diferentes tempos: o tempo dos professores em formação, o tempo das comunidades e o tempo da universidade. Embora alguns profissionais do museu tenham mencionado as dificuldades em conceber e realizar uma exposição através de um processo colaborativo que traz toda uma complexidade de sujeitos e tempos, todos foram unânimes em considerar a riqueza da experiência proposta. 


\section{O MPEG e a abertura de sua reserva técnica: as experiências da etnomuseologia}

O Museu Paraense Emílio Goeldi (MPEG) foi constituído em Belém em 1866. Ocupando uma área de mais de $2.000 \mathrm{~m}^{2}$, o MPEG abriga importante acervo arqueológico, etnográfico, de ciências naturais e de obras raras, totalizando mais de 30 mil bens musealizados. Em seu acervo indígena mais de 54 povos estão ali representados em diversos objetos.

No Brasil, o conceito "etnomuseologia" vem sendo empregado nas últimas décadas persistindo ainda pouco teorizado. Em artigo de 1994, Berta Ribeiro utilizou esse conceito sem explicitar claramente seus pressupostos. Há suposições de que tal conceito decorre de mudanças provocadas no ambiente museal pelo movimento da Nova Museologia e da museologia social. Glenn Shepard o emprega para nomear alguns processos compartilhados com povos indígenas, desenvolvidos recentemente pelo MPEG. A partir de experiências nesse museu, a "etnomuseologia visa engajar os povos indígenas em um diálogo com sua cultura material", comportando uma diversidade de conceitos, expectativas e atitudes desses povos em relação às coleções etnográficas (Shepard et al., 2017, p. 765).

A abordagem da etnomuseologia implementada no MPEG propõe que os museus não funcionem apenas para visitantes e pesquisadores tomarem consciência através dos bens materiais preservados. A partir de uma visão crítica, essa abordagem busca "tornar o outro presente", colocando os povos em novo diálogo com (e sobre) seus patrimônios e "objetiva enriquecer o campo da museologia com categorias indígenas relativas aos objetos culturais, materiais e imateriais".

A etnomuseologia também faz reflexões críticas sobre os diversos processos culturais que "fazem patrimônio", contextualizando sempre as coleções, a sua história, os seus modos de aquisição, a salvaguarda e a exposição das peças. Essa abordagem também revisita os valores e significados atribuídos aos objetos, via as relações singulares que cada povo mantém com eles. Portanto, a etnomuseologia exige parcerias efetivas entre povos indígenas e instituições museais. (Shepard et al., 2017, p. 767).

A partir de uma série de demandas das comunidades indígenas por um diálogo com sua cultura material musealizada, vários projetos se iniciaram no âmbito 
da coleção etnográfica da Reserva Técnica Curt Nimuendajú, no MPEG, formada em 1870. A despeito da singularidade de cada um dos projetos, a intenção é a de colocar em diálogo pesquisadores e representantes dos povos indígenas para recontextualizar os objetos musealizados. A proposição ancora-se na participação efetiva dos povos indígenas, resultando na articulação entre pesquisadores, povos indígenas e coleções (Gallois, 1991). O pesquisador é, então, um intermediário que facilita a formação de pesquisadores indígenas para que eles assumam com protagonismo a produção de conhecimento sobre seu próprio patrimônio cultural.

A antropóloga Lucia Hussak van Velthem, curadora da coleção etnográfica do MPEG entre 1985 a 2008, tendo reassumido essa curadoria, abriu o acervo para acesso aos povos indígenas. Entre outras iniciativas do MPEG na perspectiva da colaboração com indígenas, destacam-se pesquisas compartilhadas e concepção de exposições entre antropólogos e povos indígenas. Recentemente, o MPEG desenvolveu um trabalho de museologia colaborativa com o povo Ka'apor, uma parceria com o Museum Volkenkunde de Leiden, nos Países Baixos.

Os indígenas vieram visitar o acervo etnográfico em grupos de quatro a seis pessoas, por visita. Foram feitas três visitas, de uma semana, pelos Mebêngôkre-Kayapó, e uma visita pelos Baniwa, em momentos separados ao longo de quatro anos do projeto, o qual também envolveu repetidas idas da equipe do MPEG a campo, para diversas comunidades Mebêngôkre-Kayapó e Baniwa. (Shepard et al., 2017, p. 768).

Além disso, nove jovens indígenas foram formados para realizar o registro audiovisual em suas aldeias, que receberam equipamentos como filmadoras. A equipe do MPEG constatou as diferentes concepções que cada povo tem sobre os objetos, favorecendo uma análise conjunta que complementou a documentação já existente sobre o acervo. Para os envolvidos revelaram-se conceitos diferentes e, às vezes, divergentes entre os museólogos e os indígenas. Se por um lado a equipe do MPEG revela respeito frente aos conceitos indígenas que dinamizam a própria prática museológica, por outro eles reconhecem os desafios que esse fazer "com" os indígenas traz ao campo museal.

Os pesquisadores do museu reconhecem que além de redefinir e melhorar a sistematização da documentação sobre os objetos, o trabalho com os interlocutores indígenas viabiliza a formação técnica de indígenas com uso de 
tecnologias digitais. Essa qualificação permite que esses indígenas contribuam em processos de revalorização e reinvenção cultural em sua própria etnia.

Outra iniciativa colaborativa do MPEG em que Lucia van Velthem tem participação direta é a articulação entre os museus da Amazônia e os povos indígenas através da Rede dos Museus da Amazônia ou Amazonian Museum Network. Essa rede de museus, iniciada em 2010, envolve o próprio MPEG, o Musée des cultures guyanaises, de Caiena (Guiana Francesa), e o Stichting Surinaams Museum, de Paramaribo (Suriname), e tem entre as principais intenções a digitalização dos acervos desses museus e sua disponibilização no website da rede. Outra intenção, em andamento, é a aproximação dos povos indígenas do Planalto das Guianas a esses acervos.

\section{Reflexões finais}

Se nos anos 1990 Berta Ribeiro (1994) se preocupava com a possibilidade do desenvolvimento de pesquisas nas reservas técnicas dos museus etnográficos no Brasil, atualmente Athias e Gomes (2016) propõem outra problematização: compreender e conceituar museus indígenas em uma perspectiva antropológica contemporânea. Lima Filho e Athias (2016, p. 80), por sua vez, suscitam outros questionamentos: "como fazer pesquisas nos museus envolvendo esses 'outros'? Como trazer suas preocupações para os museus?"

As reflexões desses pesquisadores revelam preocupações em torno de fazeres e saberes que podem ser construídos de diferentes formas. Lima Filho e Athias (2016) falam, por exemplo, que os museus etnográficos precisam cada vez mais incorporar narrativas na $1^{a}$ pessoa do plural, ou seja, "nós" - pesquisadores (antropólogos, museólogos e outros) - com os detentores do patrimônio musealizado.

O que temos verificado na contemporaneidade é uma miríade de fazeres colaborativos no âmbito dos museus etnográficos ou com coleções etnográficas com povos indígenas. As relações que se estabelecem entre antropólogos, profissionais de museus e indígenas vão desde meras e rápidas consultas a efetivas e duradouras parcerias.

Como indicou Lucia van Velthem (2016), uma das principais pautas atuais na relação entre museus, coleções e povos indígenas está no ir e vir entre esses 
interlocutores. Assim, são as "negociações" que estão em jogo. E o que temos observado sobre essas relações? Aqui ainda não nos é possível chegar a classificações ou sintetizações a partir de nossos dados, mas notamos por um lado um forte engajamento de alguns antropólogos e profissionais de museus e por outro cada vez mais um posicionamento critico e uma cobrança sistemática dos povos indígenas. Eles questionam, discordam, não aceitam. O campo das relações está intenso mas muito produtivo, revelando por vezes resultados interessantes, por vezes ambiguidades e desencontros.

Assim, talvez seja possível reafirmar o que muitos já disseram: o valor das coleções etnográficas está para além das pesquisas. Certamente, observamos que acervos estudados com indígenas têm possibilitado inúmeras e diversas apropriações que não aquelas exclusivamente acadêmicas. A inclusão dos ameríndios em processos de curadoria de exposições, por exemplo, tem efetivamente despertado diferentes memórias.

Se Clifford (2016) nos anos 1990 discorria sobre museus como "zonas de contato", ou seja, como lugares de encontros e trocas entre profissionais dos museus, antropólogos, pesquisadores e os grupos representados pelos objetos musealizados, indicando já naquele momento as dificuldades desses encontros, hoje nos parece que esses contatos se ampliaram. Os museus são também zonas de negociações e, por vezes, zonas de conflitos e disputas. No que tange às relações entre antropólogos, profissionais de museus e povos indígenas, essas zonas de contatos, negociações e conflitos muitas vezes são complexas e difíceis, mas também são alvissareiras, revelando novos mundos de compartilhamentos e de futuros possíveis.

\section{Referências}

ABREU, R. Entre o universal e o singular, o museu. Notas sobre a experiência dos índios wajãpi no Museu do Índio. In: BITTENCOURT, J. N.; BENCHETRIT, S. F.; TOSTES, V. L. B. História representada: o dilema dos museus: livro do seminário internacional. Rio de Janeiro: Livros do Museu Histórico Nacional, 2003. p. 157-173.

ABREU, R. Museus etnográficos e práticas de colecionamento: antropofagia dos sentidos. Revista do Patrimônio Histórico e Artístico Nacional, v. 31, p. 100-125, 2005. 
ABREU, R. Tal antropologia, qual museu?. In: ABREU, R.; CHAGAS, M.; SANTOS, M. (org.). Museus, coleções e patrimônios: narrativas polifônicas. Rio de Janeiro: Garamond, 2007. p. 138-178.

ABREU, R. Kuahí Museum (film). Vibrant: Virtual Brazilian Anthropology, Brasília, v. 10, n. 1, Jan./June 2013. Disponível em: http://www.vibrant.org.br/issues/v10n1/ regina-abreu-kuahi-museum-film/. Acesso em: 10 jan. 2018.

ABREU, R. Museus indígenas no Brasil: notas sobre as experiências Tikuna, Wajãpi, Karipuna, Palikur, Galibi-Marworno e Galibi Kali'na. In: FAULHABER, P.; DOMINGUES, H. M. B.; BORGES, L. C. Ciências e fronteiras. Rio de Janeiro: Mast, 2014. p. 285-313.

ABREU, R. Patrimonialização das diferenças e os novos sujeitos de direito coletivo no Brasil. In: TARDY, C.; DODEBEI, V. (org.). Memória e novos patrimônios. Marseille: OpenEdition Press, 2015. v. 1, p. 67-93.

AMES, M. M. Museums, the public and anthropology: an examination on anthropology and museums in the western world. Vancouver: University of British Columbia, 1985. (Ranchi Anthropology Series).

AMES, M. M. Cultural empowerment and museum: opening up anthropology through collaboration. In: PEARCE, S. (ed.). Objects of knowlodge. London: Athlon, 1990. p. 158-173.

AMES, M. M. Cannibal tours and glass boxes: the anthropology of museums. Vancouver: University of British Columbia, 1992.

ANDERSON, B. Comunidades imaginadas: reflexões sobre a origem e a difusão do nacionalismo. São Paulo: Companhia das Letras, 2008.

ARANTES NETO, A. Prefácio. Revista do Patrimônio Histórico e Artístico Nacional (Museus), v. 31, 2005.

ATHIAS, R. Museus, objetos etnográficos e pesquisa antropológica: um debate atual. Revista Anthropológicas, v. 26, n. 1, p. 231-250, 2015.

ATHIAS, R.; GOMES, A. Coleções etnográficas, museus indigenas e processos museológicos. Recife: EdUFPE, 2016.

BALLESTRIN, L. América Latina e o giro decolonial. Revista Brasileira de Ciência Política, Brasília, n. 11, p. 89-117, maio/ago. 2013.

BESSA FREIRE, J. R. A descoberta do museu pelos índios. In: ABREU, R.; CHAGAS, M. (org.). Memória e patrimônio: ensaios contemporâneos. Rio de Janeiro: Lamparina, 2009. p. 217-253. 
BHABHA, H. O local da cultura. Belo Horizonte: Ed. UFMG, 1998.

BOURDIEU, P. A distinção: crítica social do julgamento. São Paulo: Edusp; Porto Alegre: Zouk, 2007.

BRASIL. Constituição da República Federativa do Brasil: de 5 de outubro de 1988. São Paulo: Atlas, 1992.

BRASIL. Ministério da Cultura. Política Nacional de Museus: memória e cidadania. Brasília, 2003.

BRASIL. Ministério da Cultura. Política Nacional de Museus. Brasília, 2007.

CARVALHO, L. M. de. Waldisa Rússio e Tereza Scheiner: dois caminhos, um único objetivo: discutir museu e museologia. Revista Museologia e Patrimônio, Rio de Janeiro, v. 4, n. 2, p. 147-158, 2011.

CHAGAS, M. A imaginação museal: museu, memória e poder em Gustavo Barroso, Gilberto Freyre e Darcy Ribeiro. Rio de Janeiro: Ibram: Garamond, 2009.

CHAGAS, M.; GOUVEIA, I. Museologia social: reflexões e práticas (à guisa de apresentação). Cadernos do CEOM, ano 27, n. 41, 2014. Disponível em: https://bell.unochapeco.edu.br/revistas/index.php/rcc/article/download/2592/1523. Acesso em: 9 ago. 2017.

CLIFFORD, J. Museums as contact zone. In: CLIFFORD, J. Routes: travel and translation in the late twentieth century. Cambridge: Harvard University Press, 1997. p. 188-219.

CLIFFORD, J. Museus como zonas de contato. Tradução Alexandre Barbosa de Souza e Valquiria Prates. Periódico Permanente, n. 6, 2016. Disponível em: http://www. forumpermanente.org/revista/numero-6-1/conteudo/museus-como-zonas-de-cont ato?searchterm=james+clifford. Acesso em: 20 fev. 2017.

CURY, M. X. Museus em conexões: reflexões sobre uma proposta de exposição. Revista IBICT, Brasília, v. 42, n. 3, p. 471-484, set./dez. 2013.

CURY, M. X.; SILVA, F. A. O seminário “Museus, identidades e patrimônio cultural”: MAE/USP. Revista do Museu de Arqueologia e Etnologia, São Paulo, supl. 7, p. 4-8, 2008.

CURY, M. X.; VASCONCELLOS, C.; ORTIZ, J. Questões indígenas e museus: debates e possibilidades. Brodowski: ACAM Portinari; São Paulo: MAE/USP: SEC/SP, 2012.

DESVALÉES, A.; MAIRESSE, F. (ed.). Conceitos-chave de museologia. Tradução Bruno Brulon Soares e Marilia Cury. São Paulo: Comitê Brasileiro do Conselho Internacional de Museus: Pinacoteca do Estado de São Paulo: Secult, 2013. 
DIAS, N. Le Musée d’Ethnographie du Trocadéro (1878-1908): anthropologie et muséologie en France. Paris: Éditions du Centre National de la Recherche Scientifique, 1991.

DIAS, N. Antropologia e museus: que tipo de diálogo?. In: ABREU, R.; CHAGAS, M.; SANTOS, M. (org.). Museus, coleções e patrimônios: narrativas polifônicas. Rio de Janeiro: Garamond, 2007. p. 126-137.

DIAS, N. A antropologia ainda precisa de museus?. Museologia e Interdisciplinaridade, Brasília, v. 2, n. 4, maio/jun. 2013. Disponível em: http://periodicos.unb.br/index. php/museologia/article/view/9629/7108. Acesso em: 20 fev. 2017.

DOMINGUES, J. Programa cultura viva: políticas culturais para a emancipação das classes populares. Rio de Janeiro: Luminária Academia, 2010.

DUARTE, A. Nova museologia: os pontapés de saída de uma abordagem ainda inovadora. Revista Museologia e Patrimônio, Rio de Janeiro, v. 6, n. 2, p. 99-117, 2013. Disponível em: http://revistamuseologiaepatrimonio.mast.br/index.php/ppgpmus/article/ viewFile/248/239. Acesso em: 20 fev.2017.

DURAND, J. Y. Este obscuro objeto do desejo etnográfico: o museu. Etnográfica, v. 11, n. 2, p. 373-386, nov. 2007.

DUTRA, M. R. Curadoria compartilhada na experiência de mediação cultural do Museu de Arte Contemporânea do Ceará. 2014. Dissertação (Mestrado em Artes Visuais) - Universidade Federal de Pernambuco, Recife, 2014.

FRANÇOZO, M.; BROEKHOVEN, L. Dossiê “Patrimônio indígena e coleções etnográficas". Boletim do Museu Paraense Emílio Goeldi: Ciências Humanas, v. 12, n. 3, p. 709-711, set./dez. 2017.

GALLOIS, D. O acervo etnográfico como centro de comunicação intercultural. Ciências em Museus, v. 1, n. 2, p. 137-142, 1991.

GARCÍA CANCLINI, N. Diversidade e direitos na interculturalidade global. Revista Itaú Cultural, São Paulo, n. 8, p. 143-152, abr./jul. 2009.

GORDON, C.; SILVA, F. A. Objetos vivos: a curadoria da coleção etnográfica Xikrin-Kayapó no Museu de Arqueologia e Etnologia - MAE/USP. Estudos Históricos, Rio de Janeiro, n. 36, p. 93-110, 2005.

HALL, S. Quando foi o pós-colonial? Pensando no limite. In: HALL, S. (org.). Da diáspora: identidades e mediações culturais. Belo Horizonte: Ed. UFMG, 2009. p. 95-120.

INSTITUTO BRASILEIRO DE MUSEUS. Guia dos museus brasileiros. Brasília, 2011.

KREPS, C. F. Liberating culture: cross-cultural perspective on museums, curation and heritage preservation. London: Routledge, 2003. 
L'ESTOILE, B. de. Le goût des autres: de l'exposition coloniale aux arts premiers. Paris: Flammarion, 2007.

LIMA FILHO, M.; ATHIAS, R. Dos museus etnográficos às etnografias dos museus: o lugar da antropologia na contemporaneidade. In: RIAL, C.; SCHWADE, E. (org.). Diálogos antropológicos contemporâneos. Rio de Janeiro: ABA, 2016. p. 71-83.

MOUTINHO, M. C. Sobre o conceito de museologia social. Cadernos de Museologia, Porto, n. 1, 1993. Disponível em: http://revistas.ulusofona.pt/index.php/cadernosociomuseologia/article/view/467. Acesso em: 9 ago. 2017.

MOUTINHO, M. C. Definição evolutiva de sociomuseologia: proposta de reflexão. Cadernos CEOM, Chapecó, v. 27, n. 41, p. 423-427, 2014. Disponível em: https://bell. unochapeco.edu.br/revistas/index.php/rcc/article/view/2617. Acesso em: 10 ago. 2017.

MOUVEMENT international pour une nouvelle Muséologie: règlements généraux. [S.l.]: [s.n.], 1987. Disponível em: http://www.minom-icom.net/_old/signud/DOC\%20 PDF/198702104.pdf. Acesso em: 7 ago. 2017.

MUSEU DO ÍNDIO. Seminário Gestão de acervos culturais em centros de formação, documentação, de cultura e Museus Indigenas no Brasil. Documento final. Saquarema: Funai, 2013.

PÉREZ DE CUÉLLAR, J. Nossa diversidade criadora: relatório da Comissão Mundial de Cultura e Desenvolvimento. Campinas: Papirus; Brasília, Unesco, 1997.

RIBEIRO, B. Etnomuseologia: da coleção à exposição. Revista do Museu de Arqueologia e Etnologia, São Paulo, n. 4, p. 189-201, 1994.

RIVIÈRE, G. H. La museología. Madrid: Akal, 1993.

RUSSI, A. Tamiriki, pata yotono kwama: a reconstrução de uma casa, a valorização de uma cultura e o protagonismo dos ameríndios Kaxuyana às margens do rio Cachorro (Orximiná-PA). 2014. Tese (Doutorado em Memória Social) - Universidade Federal do Estado do Rio de Janeiro, Rio de Janeiro, 2014.

SAHLINS, M. O "pessimismo sentimental” e a experiência etnográfica: por que a cultura não é um "objeto" em vias de extinção (parte 2). Mana, Rio de Janeiro, v. 3, n. 2, p. 103-150, 1997.

SAID, E. Orientalismo: o Oriente como invenção do Ocidente. São Paulo: Companhia de Bolso, 2007.

SANTACANA MESTRE, J.; HERNÁNDEZ CARDONA, F. X. Museología crítica. Gijón: Trea, 2006. 
SCHWARCZ, L. K. A “Era dos museus de etnografia” no Brasil: o Museu Paulista, o Museu Nacional e o Museu Paraense em finais do XIX. In: FIGUEIREDO, B. G.; VIDAL, D. G. (org.). Museus: dos gabinetes de curiosidades à museologia moderna. 2. ed. Belo Horizonte: Fino Traço, 2013. p. 119-143.

SHELTON, A. Questioning locality: the UBC Museum of Anthropology and its hinterlans. Etnográfica, v. 11, n. 2, p. 387-406, 2007.

SHEPARD, G. et al. Objeto, sujeito, inimigo, vovô: um estudo em etnomuseologia comparada entre os Mebêngôkre-Kayapó e Baniwa do Brasil. Boletim do Museu Paraense Emílio Goeldi: Ciências Humanas, v. 12, n. 3, p. 765-787, set./dez. 2017.

VARINE, H. As raízes do futuro: o patrimônio a serviço do desenvolvimento local. Porto Alegre: Medianiz, 2013.

VELTHEM, L. H. van. Objets de memóire: indiens, colletions et musées au Brésil. Arquivos do Centro Cultural Calouste Gulbenkian, n. 45, p. 133-149, 2003.

VELTHEM, L. H. van. O objeto etnográfico é irredutível? Pistas sobre novos sentidos e análises. Boletim do Museu Paraense Emílio Goeldi: Ciências Humanas, v. 7, n. 1, p. 51-66, jan./abr. 2012.

VELTHEM, L. H. van. Prefácio. In: ATHIAS, R.; GOMES, A. Coleções etnográficas, museus indigenas e processos museológicos. Recife: EdUFPE, 2016.

Recebido: 30/01/2018 Aceito: 05/11/2018 | Received:1/30/2018 Accepted:11/5/2018 